\title{
Congenital toxoplasmosis: evaluation of serological methods for the detection of anti-Toxoplasma gondii IgM and IgA antibodies
}

\author{
IMX Rodrigues, AM Castro, MBF Gomes, WN Amaral, MM Avelino/ ${ }^{+}$ \\ Hospital das Clínicas, Universidade Federal de Goiás, 1a Avenida s/n, Setor Universitário, 74605-050 Goiânia, GO, Brasil
}

\begin{abstract}
A study was carried out to evaluate the presence of serological markers for the immunodiagnosis of the vertical transmission of toxoplasmosis. We tested the sensitivity, specificity and predictive values (positive and negative) of different serological methods for the early diagnosis of congenital toxoplasmosis. In a prospective longitudinal study, 50 infants with suspected congenital toxoplasmosis were followed up in the ambulatory care centre of Congenital Infections at University Hospital in Goiânia, Goiás, Brazil, from 1 January 2004-30 September 2005. Microparticle Enzyme Immunoassay (MEIA), Enzyme-Linked Fluorescent Assay (ELFA) and Immune-Fluorescent Antibody Technique (IFAT) were used to detect specific IgM anti-Toxoplasma gondii antibodies and a capture ELISA was used to detect specific IgA antibodies. The results showed that 28/50 infants were infected. During the neonatal period, IgM was detected in $39.3 \%$ (11/28) of those infected infants and IgA was detected in $21.4 \%$ (6/28). The sensitivity, specificity and predictive values (positive and negative) of each assay were, respectively: MEIA and ELFA: 60.9\%, 100\%, 100\%, 55.0\%; IFAT: 59.6\%, 91.7\%, 93.3\%, 53.7\%; IgA capture ELISA: 57.1\%, 100\%, 100\%, 51.2\%. The presence of specific IgM and IgA antibodies during the neonatal period was not frequent, although it was correlated with the most severe cases of congenital transmission. The results indicate that the absence of congenital disease markers (IgM and IgA) in newborns, even after confirming the absence with several techniques, does not constitute an exclusion criterion for toxoplasmosis.
\end{abstract}

Key words: congenital toxoplasmosis - specific IgM identification - specific IgA identification - diagnosis

Maternal primary infection by Toxoplasma gondii acquired during pregnancy is of great importance since it also poses a risk of infection to the foetus and a number of serious sequelae in the infant. Approximately $40 \%$ of infected pregnant women transmit toxoplasmosis to their foetuses and this percentage is higher when the infection occurs in the third trimester. The incidence of congenital toxoplasmosis is variable, ranging from one in 1,000-one in 12,000 births (Guerina et al.1994) in various countries and in Goiânia, Goiás (GO), Brazil, Rodrigues (2006) found it to be six in 1,000 live newborns.

Both precocious diagnosis of toxoplasmosis and suitable anti-parasitic treatment of pregnant women have shown to be effective in reducing transmission severity, although they do not greatly alter the possibility of foetal infection (Foulon et al. 1999). The clinical spectrum of congenital infection by $T$. gondii ranges from apparent developmental alterations at birth, with high perinatal morbidity and mortality (microcephaly, intrauterine growth retardation and hydrocephaly), to subclinical infection, with a risk of developing retinochoroiditis and/ or later complications (Roizen et al. 1995).

Aiming to reduce the sequelae caused by this protozoan, definite diagnosis of congenital infection is mandatory and must be promptly carried out. Serologi-

Financial support: Secretaria Municipal de Saúde de Goiânia + Corresponding author: mariza.avelino@gmail.com

Received 5 March 2008

Accepted 3 March 2009 cal tests are the fastest way to diagnose this infection since they can indicate the presence of two classes of immunoglobulins that do not cross placental barrier in the newborn or nursing infant serum: anti-T. gondii IgM and IgA (Remington et al. 2001).

Demonstration of specific IgA anti-Toxoplasma antibodies have been the recommended antibody isotype for diagnosing neonatal infection because they can be as sensitive as, or more sensitive than, the demonstration of IgM antibodies (Stepick- Biek et al. 1990). By contrast, the presence of specific IgG antibodies may only represent transmission of maternal antibodies, which disappear in the first year of life.

There are many difficulties in diagnosing congenital toxoplasmosis; for example, approximately $80 \%$ of infected newborns are asymptomatic at birth and may not present any manifestation of this infection for years. However, this does not prevent the late appearance of lesions, mainly in the eyes and brain, which can lead to blindness or mental retardation (Caiaffa et al. 1993). Thus, the need for sensitive and specific serological methods for the precocious diagnosis of congenital toxoplasmosis prompted this study.

\section{MATERIAL AND METHODS}

A prospective longitudinal study of newborns with suspected congenital toxoplasmosis was carried out in Hospital das Clínicas (Universidade Federal de Goiás), in Goiânia, GO, a capital city in the Midwestern Region of Brazil, from 1 January 2004-30 September 2005. The project was approved by the Ethical Committee of Research of Hospital das Clínicas and all mothers of the newborns included in this investi- 
gation signed a Free and Informed Consent form. The maternity ward of Hospital das Clínicas is a reference centre for the diagnosis and treatment of newborns with suspected congenital toxoplasmosis and receives pregnant women diagnosed with acute toxoplasmosis during pregnancy from all of the Health Units of Goiânia and other cities in GO.

The Pregnant Protection Program sorted the women with suspected acute infection by identifying specific IgM anti-T. gondii antibodies in blood samples taken from the digital pulp (filter-paper ELISA test) at the first prenatal check-up. The presence of these antibodies was confirmed by an ELISA test carried out on peripheral blood samples, followed by IgG avidity test. A low level of IgG avidity $(<25 \%)$ indicated the acute phase of $T$. gondii infection. Moreover, since other serological reactions were performed, the probability of cross-reactivity and/or misdiagnosis of other infections, such as syphilis, rubella, hepatitis B, hepatitis C, HIV, HTLV-1, Chagas disease, herpes virus and cytomegalovirus, is remote.

Inclusion criteria were: (i) mother's acceptance to participate in this research and (ii) final conclusion whether vertical transmission was present. Exclusion criteria were: (i) no return to the service and (ii) inconclusive toxoplasmosis diagnosis.

The selected women were sent to the Reference Service of the hospital, where they underwent exams after 20 weeks of pregnancy to diagnose infections in samples collected by cordocentesis and amniocentesis. At the time of delivery, the women were directed to the maternity ward of the same hospital and samples were taken from the umbilical cord of all newborns with suspected congenital toxoplasmosis. These samples were tested for the detection of specific $\operatorname{IgM}$ and $\operatorname{IgG}$ anti-T. gondii antibodies.

In this study, 50 infants born to mothers with acute $T$. gondii infection were followed until the congenital toxoplasmosis diagnostic was concluded and one of them was a possible case of $T$. gondii reinfection during pregnancy. Blood samples of these individuals were tested using a Microparticle Enzyme Immunoassay (MEIA), an Enzyme-Linked Fluorescent Assay (ELFA) and an Immune-Fluorescent Antibody Technique (IFAT) to detect specific IgM anti-T. gondii antibodies. Then they were stored at $-20^{\circ} \mathrm{C}$ until detection of specific IgA by a double-sandwich ELISA (capture). The MEIA was evaluated with automated equipment (Axsym, Abbott) to detect anti-T. gondii $\operatorname{IgG}$ and $\operatorname{IgM}$ antibodies in the blood samples of the newborns. Reference values for IgG were: $>3 \mathrm{UI} / \mathrm{mL}$ : reactive; between 2-3 UI/mL: indeterminate; and $<2 \mathrm{UI} / \mathrm{mL}$ : nonreactive. Reference values for IgM were: $>0.600 \mathrm{UI} / \mathrm{mL}$ : reactive; between $0.500-0.600 \mathrm{UI} /$ $\mathrm{mL}$ : indeterminate; and $<0.500 \mathrm{UI} / \mathrm{mL}$ : nonreactive. Blood samples were sent to a private laboratory to detect anti-T. gondii IgM antibodies using ELFA (VIDAS, Bio-Mérieux) and IFAT (Camargo \& Leser 1976). Also, double-sandwich ELISA (capture) was used to detect specific IgA anti-T. gondii. Reference values for IgM using ELFA were: $<0.55 \mathrm{UI} / \mathrm{mL}$ : nonreactive; $>0.55$ and $<0.65 \mathrm{UI} / \mathrm{mL}$ : indeterminate; and $>0.65 \mathrm{UI} / \mathrm{mL}$ : reactive (Bio-Mérieux Instruction Manual Toxo-M). Reference values for IFAT were: $<1 / 10$ : nonreactive; and $\geq$
1/10: reactive. Reference values for specific IgA were: $<4.5 \mathrm{UA} / \mathrm{mL}$ : nonreactive; between 4.5-5 UA/mL: indeterminate; and $>5 \mathrm{UA} / \mathrm{mL}$ : reactive. The ELFA was performed because it captures IgM antibodies, avoids false-positive (due to the presence of rheumatoid factor) and false-negative (due to excess $\operatorname{IgG}$ ) reactions, and presents sensitivity and specificity comparable to the immunosorbent agglutination assay (ISAGA) of 93.5\% and $99.3 \%$, respectively.

In order to prevent possible cross-reactions of $\operatorname{IgM}$ anti-T. gondii antibodies with anti-cytomegalovirus, rubella, Epstein-Barr virus antibodies and anti-syphilis antibodies, serology for these viruses was carried out in the reactive IgM samples using MEIA for the first two, indirect agglutination for the third and Venereal Disease Research Laboratory test for the last group.

Congenital toxoplasmosis diagnosis was achieved using the following service protocol: identification of specific IgM and/or IgA anti-T. gondii antibodies in the umbilical cord of newborns with suspected congenital toxoplasmosis, approximately two weeks after birth, confirmed in peripheral blood; presence of characteristic clinical signs (retinochoroiditis or intracranial calcification); identification of protozoan through culture and inoculation in mice followed by histopathological exam of the brains of inoculated animals; identification of specific anti-T. gondii antibodies in the cephalo-rachidian liquid (CRL) of newborns with suspected congenital infection; IgG persisting for more than six months in infants treated since birth; detection of specific IgM during laboratory control or detection of antibodies after ceasing treatment of infants who received sulfadiazine in association with pyrimethamine and folinic acid since birth (Berger et al. 1992). The recognised gold standard diagnostic method for congenital toxoplasmosis has been the isolation of the parasite. However, specific IgM and IgA anti-T. gondii antibodies, which are not transmitted through the placenta, have also been considered serological markers of vertical transmission. Furthermore, characteristic symptoms, such as retinochoroiditis, diffuse intracranial calcifications, microcephaly and hydrocephaly in the newborn (in the absence of serological positivity for syphilis, rubella, cytomegalovirus, HIV, hepatitis B and C, herpes and Chagas disease in the mother) have also been considered diagnostic, since these symptoms indicate the neuro-ophthalmic form of toxoplasmosis. The presence of specific antibodies in CRL, followed or not by the growth of cells or proteins and without cranial volume changes, was considered a possible acute meningitic form of congenital toxoplasmosis and the infants were considered infected until confirmation of toxoplasmosis through other results was provided, such as: persistence of antibodies six months after birth; positivity of antibodies after ceasing treatment in the case of past negative exams; increase of $\operatorname{IgG}$ antibodies during the follow-up; or detection of retinochoroiditis during the follow-up.

Serology to detect $\operatorname{IgG}$ and $\operatorname{IgM}$ in the infants using MEIA was carried out every two months until 12 months of age throughout follow-up. Sensitivity, specificity and predictive values (positive and negative) of 
IgM antibodies were determined using MEIA, ELFA and IFAT and of IgA antibodies using a capture ELISA to diagnose congenital toxoplasmosis. Calculations were made using Thomas Bayes's mathematical formulas (Kawamura 2002).

Data were analysed using Excel version 2007 (Microsoft, Brazil) and EPI-INFO (version 6.04, CDC, USA). The statistical significance level was set at $p<0.05$ with a $95 \%$ confidence interval.

\section{RESULTS}

Among the 50 newborns, 28 were infected. In the 22 non-infected patients, $\operatorname{IgG}$ antibodies disappeared from peripheral blood between the fourth and 10th months of age (negative results were confirmed after ceasing treatment). The liquor exam was normal and presented negative serology, both the cranial ultrasonography and the ophthalmoscopy were normal, and the infants presented normal neuropsychomotor development at one year of age.

Serology for cytomegalovirus, rubella, mononucleosis and syphilis was carried out for the samples presenting reactive specific IgM anti-T. gondii antibodies, and all were nonreactive, demonstrating that there was no crossreaction with the antibodies against these diseases.

During the neonatal period, congenital toxoplasmosis was diagnosed through laboratory exams (serology) in 11 out of the 28 infected newborns (39.3\%). This was confirmed in the first 15 days after birth based on the presence of specific IgM anti-T. gondii antibodies in the umbilical cord blood serum and also confirmed in the peripheral blood (Table I). Specific IgA was found in $21.4 \%(6 / 28)$ of the infants and the highest results for IgM coincided with IgA positivity, except for case 1.

Among the 11 newborns with serological markers of congenital infection, $90.9 \%$ (10/11) presented very high IgG titres and 72.7\% (8/11) did not undergo complementary exams for the diagnosis of foetal toxoplasmosis (Table I). One asymptomatic newborn, who had nonreactive IgM and IgA 27 days after birth, was positive for both parameters using the four techniques described two months after birth. The liquor exam was abnormal (positive serology), the opthalmoscopy was abnormal, the protozoan parasite was positive and the patient received a late serological diagnosis of congenital toxoplasmosis. Among the newborns who were infected and symptomatic at birth (10/28 - 35.7\%), 25\% (7/28) presented serological markers of vertical transmission and severe forms of congenital toxoplasmosis.

Table II shows the clinical alterations presented by the infants who had serological markers of congenital $T$. gondii infection during the neonatal period. The most severe form of congenital toxoplasmosis (neuro-ophtalmic) was present in $25 \%$ of the cases (7/28) and the presence of serological markers in their peripheral blood showed positive correlation with severity of infection.

Among the mothers of the 11 newborns with congenital toxoplasmosis markers, five were seronegative $(45.4 \%)$ in the prenatal screening (Table II) and therefore did not receive medication. Only two newborns were asymptomatic and persisted in this condition after ceasing treatment. It was also verified that the clinical manifestations were more severe in one individual who presented the highest concentrations of IgM and whose mother had not been treated previously (case 10).

In this study, we observed that there were alterations in CRL in $57.1 \%$ of the cases (16/28) and $31.2 \%$ of these $(5 / 16)$ already presented sequelae of neurotoxoplasmosis due to precocious intrauterine infection. The remaining $68.8 \%(11 / 16)$ were in the acute phase of meningitis; six of them did not present any sequelae after ceasing specific treatment, two presented hearing deficit and two presented cortico-subcortical dysfunction (Tables I, II).

Table III displays the criteria used for the diagnosis of congenital infection in the newborns who did not present serological markers of vertical transmission. We observed that the best method for this diagnosis in our study was the identification of specific antibodies in CRL in $57.1 \%$ of the cases $(16 / 28)$, followed by the identification of protozoan in $50 \%$ of the cases $(14 / 28)$. Foetal IgM was diagnosed in $32.1 \%$ of the cases $(9 / 28)$, although this was tested in only 16 out of the 28 infected newborns (Tables I, III). Furthermore, IgM and/ or IgA were identified only two months after birth in one infant who, neither at birth nor 27 days after birth, presented serological markers of specific IgM and/or $\operatorname{IgA}$. On the other hand, lack of diagnosis and specific treatment of the pregnant women seemed to have had positive correlation with the most severe clinical forms of the congenital disease at birth. Also, it is worth mentioning that only three pregnant women underwent complementary exams for the diagnosis of foetal toxoplasmosis and used spyramicin from the diagnosis up to the time of their infant's birth.

Table IV presents the different criteria for the diagnosis of congenital toxoplasmosis as well as the importance of each criterion in the precocious diagnosis of this infection.

Table V displays the sensitivity, specificity and predictive values (positive and negative) for the tests used. Specificity of MEIA and ELFA was $100 \%$, since none of the newborns not affected by the infection presented specific IgM anti-T. gondii antibodies; their sensitivities were each $60.9 \%$, as 10 out of the 28 infected patients presented IgM antibodies using both of these techniques. Specificity of IFAT was $91.7 \%$, since two out of the 22 non-infected newborns presented false-positive results for IgM; the sensitivity of this technique was $59.6 \%$, since nine out of the 28 infected individuals presented reactive $\operatorname{IgM}$ antibodies.

According to the literature, MEIA had not been tested in newborns before this study and even though it is not a capture test, it presented specificity and sensitivity comparable to ELFA for the detection of anti-T. gondii IgM antibodies, which makes it the most indicated technique for this purpose due to its lower cost and similar efficacy.

\section{DISCUSSION}

Diagnosis of congenital toxoplasmosis is difficult due to the presence of maternal specific IgG anti-T. gondii antibodies in the newborn blood acquired through transplacental passage. Nevertheless, IgM and IgA anti- 
TABLE I

Immunologic and parasitologic profile of 11 newborns presenting serological markers of congenital toxoplasmosis vertical transmission during the neonatal period using different techniques

\begin{tabular}{|c|c|c|c|c|c|c|c|c|}
\hline $\mathrm{N}$ & $\begin{array}{c}\text { MEIA } \\
\text { IgG }\end{array}$ & $\begin{array}{c}\text { MEIA } \\
\text { IgM }\end{array}$ & ELFA IgM & $\begin{array}{c}\text { IFAT } \\
\text { IgM }\end{array}$ & $\begin{array}{c}\text { Elisa } \\
\text { IgA }\end{array}$ & Protozoan & CRL & Fetal blood \\
\hline 1 & $>300$ & NR & $1.4(\mathrm{R})$ & NR & $54.6(\mathrm{R})$ & $\mathrm{P}$ & $\mathrm{P}$ & $\mathrm{P}$ \\
\hline 2 & $>300$ & $9.203(\mathrm{R})$ & $10.6(\mathrm{R})$ & $1 / 320$ & $89.8(\mathrm{R})$ & NA & $\mathrm{N}$ & $\mathrm{N}$ \\
\hline 3 & $>300$ & $0.849(\mathrm{R})$ & $1.2(\mathrm{R})$ & $1 / 40$ & NR & $\mathrm{P}$ & $\mathrm{P}$ & NA \\
\hline 4 & $>300$ & $1.724(\mathrm{R})$ & $2.9(\mathrm{R})$ & NR & NR & $\mathrm{P}$ & $\mathrm{P}$ & $\mathrm{P}$ \\
\hline 5 & 162.1 & $6.432(\mathrm{R})$ & $8.4(\mathrm{R})$ & 1/640 (R) & $61.5(\mathrm{R})$ & $\mathrm{N}$ & $\mathrm{P}$ & NA \\
\hline 6 & $>300$ & $1.45(\mathrm{R})$ & $1.9(\mathrm{R})$ & NR & NR & $\mathrm{N}$ & $\mathrm{P}$ & NA \\
\hline 7 & 1579 & $1.946(\mathrm{R})$ & $2.6(\mathrm{R})$ & $1 / 80(\mathrm{R})$ & $72.4(\mathrm{R})$ & NA & NA & NA \\
\hline 8 & $>300$ & $2.248(\mathrm{R})$ & NR & 1/160 (R) & $95.4(\mathrm{R})$ & NA & NA & NA \\
\hline 9 & $>3000$ & $1.824(\mathrm{R})$ & $3.2(\mathrm{R})$ & $1 / 160(\mathrm{R})$ & NR & $\mathrm{P}$ & $\mathrm{P}$ & NA \\
\hline 10 & $>300$ & $14.248(\mathrm{R})$ & $12.5(\mathrm{R})$ & $1 / 1280(\mathrm{R})$ & $110.4(\mathrm{R})$ & NA & NA & NA \\
\hline 11 & $>3000$ & NR & NR & $1 / 256(\mathrm{R})$ & NR & $\mathrm{N}$ & $\mathrm{N}$ & NA \\
\hline
\end{tabular}

CRL: cephalo-rachidian liquid; ELFA: Enzyme-Linked Fluorescent Assay; IFAT: Immune-Fluorescent Antibody Technique; MEIA: Microparticle Enzyme Immunoassay; N: negative; NA: not applicable; NR: nonreactive; P: positive; R: reactive. Serology for cytomegalovirus (MEIA), rubella (MEIA), Epstein-Barr virus (indirect agglutination) and syphilis was negative.

TABLE II

Correlation between the diagnosis of toxoplasmosis of the pregnant women and the presence of clinic alterations in the newborns who presented serological markers of congenital infection during the neonatal period

\begin{tabular}{lcccccc}
\hline & \multicolumn{3}{c}{ Pregnant women } & & Newborns \\
\cline { 2 - 7 } $\mathrm{N}$ & Prenatal diagnostics & Fetal diagnosis & Treatment & Clinic signs at birth & Beginning treatment & Late clinic signs \\
\hline 1 & previous pegnancy & $\mathrm{R}$ & $\mathrm{S}$ & absence & at birth & absence \\
2 & IgM + & $\mathrm{NR}$ & $\mathrm{S}$ & absence & at birth & seizures \\
3 & seronegative & NA & none & retinochoroiditis & 3 months after birth & no recurrence \\
4 & IgM + & NA & none & neurotoxoplasmosis & no follow-up & no follow-up \\
5 & seronegative & NA & none & absence & 17 days after birth & absence \\
6 & IgM + & R & none & neurotoxoplasmosis & 2 months after birth & neurotoxoplasmosis \\
7 & seronegative & NA & none & absence & no follow-up & no follow-up \\
8 & seronegative & NA & none & neurotoxoplasmosis & 11 months & neurotoxoplasmosis \\
9 & IgM + & NA & none & neurotoxoplasmosis & at birth & neurotoxoplasmosis \\
10 & seronegative & NA & none & fatal systemic infection & deceased & deceased \\
11 & IgM + & NA & S & retinochoroiditis & at birth & no recurrence \\
\hline
\end{tabular}

NA: not applicable; NR: nonreactive; R: reactive; S: spyramicin until birth, no correlation with clinic signs in newborn. OR = $1.88(0.10<\mathrm{OR}<62.21)$.

bodies do not cross the placental barrier and when they do so at birth, they have a lifespan of only five days, which allows them to be used as serological markers of vertical transmission.

Specific IgM anti-T. gondii antibodies were not detected in $57.1 \%(16 / 28)$ of the patients presenting congenital toxoplasmosis, which confirms the low sensitivity of this technique for newborns, as is widely seen in the literature. This might have happened due to technical difficulties in reading the laboratory results because of: (i) maternal IgG binding in high titres to the binding site of IgM; (ii) foetal inhibition of antibody production because of high titres of maternal antibodies in the foetus's blood; or (iii) the decrease of parasitaemia as a consequence of the mother's treatment (Pinon et al. 2001). This finding shows that the pregnant woman's treatment modifies the foetus and newborn immune response as a result of the significant reduction of $T$. gondii circulating antigens.

The low possibility of diagnosis using serological techniques demonstrates the need for using several criteria for the precocious detection of congenital toxoplasmosis. In 
TABLE III

Distribution of diagnostic criteria for one newborn presenting late serological markers and 16 newborns that did not present serological markers of congenital toxoplasmosis during the neonatal period

\begin{tabular}{lcccc}
\hline N & $\begin{array}{c}\text { Clinic signs } \\
\text { at birth }\end{array}$ & $\begin{array}{c}\text { Late clinic } \\
\text { signs }\end{array}$ & $\begin{array}{c}\text { Protozoan } \\
\text { identification }\end{array}$ & $\begin{array}{c}\text { Fetal } \\
\text { blood }\end{array}$ \\
\hline 12 & absence & absence & $\mathrm{P}$ & $\mathrm{NA}$ \\
13 & absence & absence & $\mathrm{P}$ & $\mathrm{P}$ \\
14 & retinochoroiditis & $\mathrm{N}$ & $\mathrm{N}$ \\
15 & absence & deafness & $\mathrm{N}$ & $\mathrm{P}$ \\
16 & deafness & absence & $\mathrm{N}$ & $\mathrm{P}$ \\
17 & absence & cortico-subcortical dysfunction & $\mathrm{N}$ & $\mathrm{P}$ \\
18 & absence & cortico-subcortical dysfunction & $\mathrm{N}$ & $\mathrm{NA}$ \\
19 & absence & absence & $\mathrm{P}$ & $\mathrm{N}$ \\
20 & absence & hydrocephaly & $\mathrm{P}$ & $\mathrm{N}$ \\
21 & hydrocephaly & absence & $\mathrm{P}$ & $\mathrm{P}$ \\
22 & absence & absence & $\mathrm{P}$ & $\mathrm{P}$ \\
23 & absence & $\mathrm{P}$ & $\mathrm{N}$ \\
24 & absence & $\mathrm{P}$ & $\mathrm{NA}$ \\
25 & absence & cortico-subcortical dysfunction & $\mathrm{P}$ & $\mathrm{N}$ \\
26 & absence & absence & $\mathrm{P}$ & $\mathrm{N}$ \\
27 & absence & absence & $\mathrm{P}$ & $\mathrm{P}$ \\
28 & neurotoxoplasmosis & absence & $\mathrm{N}$ & $\mathrm{N}$ \\
\hline
\end{tabular}

CRL: cephalo-rachidian liquid; ELFA: Enzyme-Linked Fluorescent Assay; IFAT: Immune-Fluorescent Antibody Technique; MEIA: Microparticle Enzyme Immunoassay; N: negative; NA: not applicable; P: positive. Serology for cytomegalovirus (MEIA), rubella (MEIA), Epstein-Barr virus (indirect agglutination) and syphilis was negative. 12-MEIA IgM = 1.824 (reative); ELFA = 2.4 (reative); IFAT $=1 / 80$ two months after birth.

our study, the variety of criteria employed allowed the diagnosis of 28 newborns, 19 (67.8\%) of whom started the specific treatment at birth. Precocious therapy is necessary because the development of late sequelae (in the brain and eyes) is a common occurrence. The present study showed that $57.1 \%(16 / 28)$ of the infected newborns presented alterations in CRL; $31.2 \%$ of them $(5 / 16)$ presented sequelae of neurotoxoplasmosis due to intrauterine infection; the remaining $68.8 \%(11 / 16)$ were in the acute phase of meningitis; six of them did not present any sequelae after ceasing specific treatment; two presented hearing deficit; and two presented cortico-subcortical dysfunction. These two last sequelae are considered mild since the evolution of non-treated meningitis is hydrocephaly and the intracranial calcifications can be responsible for seizures and mental retardation.

This study showed that the exam that best detected congenital toxoplasmosis was the one carried out in CRL because we found specific anti- $T$. gondii antibodies in $57.2 \%$ of the cases, followed by parasite isolation $(50 \%)$, and identification of serological markers $(42.8 \%)$, as presented in Table III. These exams permitted a confirmatory diagnosis of congenital toxoplasmosis in all 28 cases (Tables I-III). Nonetheless, one isolated criterion, such as the identification of $\operatorname{IgM}$ in neonatal screening, should not be used in place of prenatal serological tests for seroconversion surveillance since it presented a good result in only $39.3 \%$ of the infected newborns.
On the other hand, the presence of serological markers of vertical transmission was positively correlated with a higher severity of the congenital infection $63.6 \%$ (7/11) and one newborn died as a consequence of systemic toxoplasmosis. Retinochoroiditis identified at birth was observed in $18.2 \%(2 / 11)$ of the infected newborns who presented serological markers of congenital infection and in $27.3 \%(6 / 22)$ among the other infected newborns, for a total of $28.6 \%(8 / 28)$, as shown in Table IV.

Among the newborns presenting congenital toxoplasmosis, 39.3\% (11/28) showed symptoms of the infection and IgM antibodies were not detected in two of those $(18.2 \%)$ who presented the neurologic form. There is a consensus regarding congenital syphilis (Borobio et al. 1980, Serra et al. 1982, Srinivasan et al. 1983) that IgM levels are high in symptomatic newborns and can be normal or low in asymptomatic individuals (Horwitz 1980). It seems that the same remains true for toxoplasmosis, since in the present study, $70 \%$ (7/10) of the symptomatic newborns presented anti-T. gondii IgM antibodies.

The sensitivity of identifying anti-T. gondii antibodies by using three serological techniques (MEIA, ELFA and IFAT) was just $42.8 \%(12 / 28)$, a fact of great concern, as in many paediatric services the detection of this antibody with the newborn screening test is the only exam carried out in order to diagnose congenital toxoplasmosis.

Specific IgA anti-T. gondii was reactive in $25 \%$ $(7 / 28)$ of the infected newborns, presenting less sensitiv- 
TABLE IV

Evaluation of criteria for the diagnosis of congenital toxoplasmosis in 50 newborns followed-up in a longitudinal study

\begin{tabular}{|c|c|c|c|c|c|}
\hline Diagnostic criteria & $\begin{array}{c}\text { Toxoplasmosis } \\
(\%)\end{array}$ & NA & $\begin{array}{c}\text { No toxoplasmosis } \\
(\%)\end{array}$ & NA & Total \\
\hline $\operatorname{IgM}$ fetal $(+)^{a}$ & $32.1(9 / 28)$ & & $0(0 / 22)$ & & $18.0(9 / 50)$ \\
\hline IgM fetal (-) & $42.8(7 / 28)$ & & $50.0(11 / 22)$ & & $36.0(18 / 50)$ \\
\hline Total & $57.1(16 / 28)$ & $42.9(12 / 28)$ & $50.0(11 / 22)$ & $50.0(11 / 22)$ & $54.0(27 / 50)$ \\
\hline $\operatorname{IgM}(+)^{b}$ & $42.8(12 / 28)$ & & $0(0 / 22)$ & & $24.0(12 / 50)$ \\
\hline $\operatorname{Ig} M(-)$ & $57.2(16 / 28)$ & & $100.0(22 / 22)$ & & $76.0(38 / 50)$ \\
\hline Total & $100.0(28 / 28)$ & $0(0 / 28)$ & $100.0(22 / 22)$ & $0(0 / 22)$ & $100.0(50 / 50)$ \\
\hline retinochoroiditis $(+)^{c}$ & $28.6(8 / 28)$ & & $0(0 / 22)$ & & $16.0(8 / 50)$ \\
\hline retinochoroiditis (-) & $67.8(19 / 28)$ & & $100.0(22 / 22)$ & & $84.0(42 / 50)$ \\
\hline Total & $96.4(27 / 28)$ & $3.6(1 / 28)$ & $100.0(22 / 22)$ & $0(0 / 22)$ & $100.0(50 / 50)$ \\
\hline hidrocephaly $(+)^{d}$ & $21.4(6 / 28)$ & & $0 / 22$ & & $12.0(6 / 50)$ \\
\hline hidrocephaly (-) & $78.6(22 / 28)$ & & $100.0(22 / 22)$ & & $88.0(44 / 50)$ \\
\hline Total & $100.0(28 / 28)$ & $0(0 / 28)$ & $0(0 / 22)$ & $0(0 / 22)$ & $100.0(50 / 50)$ \\
\hline protozoan $(+)^{e}$ & $50.0(14 / 28)$ & & $0(0 / 22)$ & & $28.0(14 / 50)$ \\
\hline protozoan (-) & $35.7(10 / 28)$ & & $72.7(16 / 22)$ & & $52.0(26 / 50)$ \\
\hline Total & $85.7(24 / 28)$ & $14.3(4 / 28)$ & $72.7(16 / 22)$ & $27.3(6 / 22)$ & $80.0(40 / 50)$ \\
\hline $\operatorname{CRL}(+)^{f}$ & $57.2(16 / 28)$ & & $0(0 / 22)$ & & $32.0(16 / 50)$ \\
\hline CRL (-) & $32.1(9 / 28)$ & & $81.8(18 / 22)$ & & $54.0(27 / 50)$ \\
\hline Total & $89.3(25 / 28)$ & $10.7(3 / 28)$ & $81.8(18 / 22)$ & $18.2(4 / 22)$ & $86.0(43 / 50)$ \\
\hline
\end{tabular}

$a: \mathrm{RR}=2.57(1.44<\mathrm{RR}<4.59) \mathrm{p}=0.002($ Fisher exact); $b: \mathrm{RR}=2.38(1.64<\mathrm{RR}<3.45) \mathrm{p}=0.001$ (Yates corrected); $c: \mathrm{RR}=$ $2.16(1.55<\mathrm{RR}<3.0) \mathrm{p}=0.004$ (Fisher exact); CRL: chephalo-raquidian liquid; $d: \mathrm{RR}=2.00(1.49<\mathrm{RR}<2.69) \mathrm{p}=0.02($ Fisher exact); $e: \mathrm{RR}=2.60(1.60<\mathrm{RR}<4.23) \mathrm{p}=0.0005$ (Yates corrected); $f \mathrm{RR}=3.00(1.76<\mathrm{RR}<5.4) \mathrm{p}=0.00007$ (Yates corrected); NA: not applicable.

TABLE V

Sensitivity, specificity and predictive values (positive and negative) of serological reactions used for the diagnosis of congenital toxoplasmosis

\begin{tabular}{lcccc}
\hline & Sensitivity & $\begin{array}{c}\text { Specificity } \\
\%\end{array}$ & $\begin{array}{c}\text { Positive predictive value } \\
\%\end{array}$ & \multicolumn{2}{c}{$\begin{array}{c}\text { Negative predictive value } \\
\%\end{array}$} \\
\hline Technique & $\%$ & 100 & 100 & 55.0 \\
MEIA-IgM & 60.9 & 100 & 100 & 55.0 \\
IFAT-IgM & 60.9 & 91.7 & 93.3 & 53.7 \\
ELISA-IgA & 59.6 & 100 & 100 & 51.2 \\
\hline
\end{tabular}

ELFA: Enzyme-Linked Fluorescent Assay; IFAT: Immune-Fluorescent Antibody Technique; MEIA: Microparticle Enzyme Immunoassay. CI: MEIA/ELFA-IgM = 44.15-77.64; ELISA-IgA = 41.42-72.78; IFAT-IgM = 43.22-75.98.

ity (57.1\%) than MEIA (60.9\%), ELFA (60.9\%) and IFAT $(59.6 \%)$. This low sensitivity might result from the technique used (double-sandwich ELISA) and/or the treatment of pregnant women and newborns with suspected congenital infection (Pinon et al. 1996).

It should be emphasised that the suspected congenital toxoplasmosis cannot be dismissed simply by taking into consideration the absence of $\operatorname{IgM}$ and $\operatorname{IgA}$ antibodies or the negative result obtained for $\operatorname{IgG}$ antibodies, mainly for newborns who had been treated during in- trauterine and/or post-natal phases. The follow-up of the newborns with suspected congenital toxoplasmosis must be carried out in specialised centres, using all possible diagnostic resources available, so that no child suffers the consequences of misdiagnosed toxoplasmosis based solely on the absence of $\operatorname{IgM}$ or IgA antibodies.

\section{ACKNOWLEDGEMENTS}

To Maria Heloísa Mesquita, who made this scientific research possible. 


\section{REFERENCES}

Berger R, Sturchler D, Rudin C 1992. Cord blood screening for congenital toxoplasmosis: detection and treatment of asymptomatic newborns in Basel, Switzerland. Scan J Infect Dis Suppl 84: 46-50.

Borobio MV Nogales MC, Palomares SC 1980. Value of serological diagnosis in congenital syphilis. Report of nine cases. Br J Vener Dis 56: 377-380.

Caiaffa WT, Chiari CA, Figueiredo AR, Orefice F, Antunes CM 1993. Toxoplasmosis and mental retardation. Report of a case-control study. Mem Inst Oswaldo Cruz 88: 253-261.

Camargo ME, Leser PG 1976. Diagnostic information from serological tests in human toxoplasmosis. II Evolutive study of antibodies and serological patterns in acquired toxoplasmosis, as detected by hemagglutination, complement fixation, IgG and IgM-immunofluorescence tests. Rev Inst Med Trop São Paulo 18: 227-238.

Foulon W, Villena I, Stray-Pedersen B, Decoster A, Lappalainen M, Pinon JM, Jenum PA, Hedman K, Naessens A 1999. Treatment of toxoplasmosis during pregnancy: a multicenter study of impact on fetal transmission and children's sequelae at age 1 year. Am $J$ Obstet Gynecol 180: 410-415.

Guerina NG, Hsu HW, Meissner HC, Maguire JH, Lynfield R, Stechenberg B, Abroms I, Pasternack MS, Hoff R, Eaton RB, Grady GF 1994. Neonatal serologic screening and early treatment for congenital Toxoplasma gondii infection. The New England Regional Toxoplasma Working Group. N Engl J Med 330: 1858-1863.

Horwitz CA 1980. Laboratory investigation of syphilis. Postgrad Med 68: 71-76, 78-79, 81.

Kawamura T 2002. Interpretação de um teste sob a visão epidemiológica. Eficiência de um teste. Arq Bras Cardiol 79: 437-444.

Pinon JM, Chemla C, Villena I, Foudrinier F, Aubert D, PuygauthierToubas D, Leroux B, Dupouy D, Quereux C, Talmud M, Trenque T, Potron G, Pluot M, Remy G, Bonhomme A 1996. Early neona- tal diagnosis of congenital toxoplasmosis: value of comparative enzyme-linked immunofiltration assay immunological profiles and anti-Toxoplasma gondii immunoglobulin M (IgM) or IgA immunocapture and implications for postnatal therapeutic strategies. J Clin Microbiol 34: 579-583.

Pinon JM, Dumon H, Chemla C, Franck J, Petersen E, Lebech M, Zufferey J, Bessieres MH, Marty P, Holliman R, Johnson J, Luyasu V, Lecolier B, Guy E, Joynson DH, Decoster A, Enders G, Pelloux H, Candolfi E 2001. Strategy for diagnosis of congenital toxoplasmosis: evaluation of methods comparing mothers and newborns and standard methods for postnatal detection of immunoglobulin G, M, and A antibodies. J Clin Microbiol 39: 2267-2271.

Remington JS, Mcleod R, Thulliez P, Desmonts G 2001. Toxoplasmosis. In JS Remington, JO Klein, Infectious diseases of the fetus and newborn infant, 5th ed., WB Saunders, Philadelphia, p. 205-346.

Rodrigues IMX 2006. Diagnóstico pós-natal da toxoplasmose congênita através da detecção de anticorpos das classes $\operatorname{Ig} G$, IgM e IgA anti-Toxoplasma gondii, MSc thesis, Universidade Federal de Goiás, Goiânia, 115 pp.

Roizen N, Swisher CN, Stein MA, Hopkins J, Boyer KM, Holfels E, Mets MB, Stein L, Patel D, Meier P, Withers S, Remington J, Mack D, Heydemann P, Patton D, McLeod R 1995. Neurologic and developmental outcome in treated congenital toxoplasmosis. Pediatrics 95: 11-20.

Serra G, Bruschettini PL, Bonacci W, Magliano P, Mastromatteo L, Cacciabue E 1982. La lue connatale: criteri diagnostici e condotta terapeutica. Minerva Pediatr 34: 749-756.

Srinivasan G, Ramamurthy RS, Bharathi A, Voora S, Pildes RS 1983. Congenital syphilis: a diagnostic and therapeutic dilemma. $P e-$ diatr Infect Dis 2: 436-441.

Stepick-Biek P, Thulliez P, Araujo FG, Remington JS 1990. IgA antibodies for diagnosis of acute congenital and acquired toxoplasmosis. J Infect Dis 162: 270-273. 